\title{
Expired Drug (pantoprazole sodium) as a Corrosion Inhibitor for High Carbon Steel in Hydrochloric Acid Solution
}

\author{
A.S. Fouda ${ }^{1, *}$, H.Ibrahim ${ }^{2}$, S.Rashwaan ${ }^{2}$, A. El-Hossiany ${ }^{3}$, R.M. Ahmed ${ }^{1}$ \\ ${ }^{1}$ Department of Chemistry, Faculty of Science, El-Mansoura University, El-Mansoura-35516, Egypt, \\ ${ }^{2}$ Department of Chemistry, Faculty of Science, Suez Canal University. Ismailia, Egypt. \\ ${ }^{3}$ Chemist, Delta Fertilizers Company in Talkha, Egypt \\ *E-mail: $\underline{\text { asfouda@hotmail.com }}$
}

doi: $10.20964 / 2018.07 .33$

Received: 3 March 2018 / Accepted: 27 April 2018 / Published: 5 June 2018

The expired pantoprazole sodium EPS drug was studied as a corrosion inhibitor for high carbon steel (HCS) in $1 \mathrm{M} \mathrm{HCl}$ solution using mass loss (ML), potentiodynamic polarization (PP), electrochemical impedance spectroscopy (EIS) and electrochemical frequency modulation (EFM) tests. Fourier transform infrared spectroscopy (FT-IR) was utilized to identify bands of PS drug on HCS surface. Surface morphology was tested by scanning electron microscope (SEM), Atomic Force Microscopy (AFM) and Energy Dispersion Spectroscopy X-ray spectra (EDX). The effect of temperature on the corrosion process has been studied in addition of different concentrations of EPS drug. PP curves showed that the study drug is a mixed kind inhibitor. The inhibition efficiency (IP \%) was improved with improving the concentration of PS and was reduced by improving the temperature of the medium. The PS adsorbed on HCS surface was noticed to follow the Langmuir's adsorption isotherm. The outcome data gotten from electrochemical and chemical tests are in excellent agreement.

Keywords: Corrosion inhibition, $\mathrm{HCl}$, HCS, EPS drug, AFM, FT-IR, SEM

\section{FULL TEXT}

(C) 2018 The Authors. Published by ESG (www.electrochemsci.org). This article is an open access article distributed under the terms and conditions of the Creative Commons Attribution license (http://creativecommons.org/licenses/by/4.0/). 